Proceedings

\title{
Enhanced Efficiency of Inverted Perovskite Solar Cells by Passivating Hole Transport Layer with POSS +
}

\author{
Bo-Tau Liu* and Hong-Ru Lin \\ Department of Chemical and Materials Engineering, National Yunlin University of Science and Technology, \\ Yunlin 64002, Taiwan; M10615023@yuntech.edu.tw \\ * Correspondence: liubo@yuntech.edu.tw; Tel.: 886-5-552-4710; Fax: 886-5-531-2071 \\ + Presented at the 2nd International Online-Conference on Nanomaterials, \\ 15-30 November 2020; Available online: https://iocn2020.sciforum.net/.
}

Published: 15 November 2020

\begin{abstract}
The energy crisis and environmental pollution are attracting increasing attention, which made many countries implement a series of preferential policies for renewable energy. Among them, solar photovoltaic technology, which can convert solar light into electrical energy, is one of the most feasible methods for renewable energy. It not only improves environmental problems but also reduces dependence on fossil fuels. In recent years, perovskite solar cells has reviewed promising potential in solar photovoltaics owing to low process energy consumption, large-scale production, low cost, simple fabrication process, light weight, flexibility, etc. Polyhedral oligomeric silsesquioxane (POSS) featuring a hollow-cage or semi-cage structure is a new type of organicinorganic hybrid nanoparticles. POSS combines the advantages of inorganic components and organic components to become one of the most important materials. When POSS is well dispersed in the polymer matrix, it can effectively improve the thermal, mechanical, magnetic, acoustic, and surface properties of the polymer. In this study, the POSS was spin-coated as a ultra-thin passivation layer to optimize a nickel-oxide hole layer, which made perovskite solar cells feature high open circuit voltage. Experimental results showed that Coating an appropriate POSS amount to form an ultra-thin passivation layer could effectively suppress the surface defects of perovskite layers, reduce the recombination of the electron and hole, and increase the short-circuit current. As a result, the power conversion efficiency increased from 13.30 to $15.58 \%$, enhanced by $17 \%$.
\end{abstract}

Keywords: polyhedral oligomeric silsesquioxane; perovskite solar cell; passivation layer; $\mathrm{NiO} \times$

\section{Introduction}

Owing to lightweight, low cost, simple fabrication, high optical absorption coefficient, and large charge carrier diffusion length, perovskite solar cells (PSCs) have been regarded as one of the most promising photovoltaic technologies and increase rapidly in power conversion efficiency (PCE) from 3.8 to $25.2 \%$ in a very short period of time [1-4]. Compared to conventional PSCs, inverted cells with a device structure of transparent conductive oxide/hole transport layer (HTL)/perovskite/electron transport layer (ETL)/top metal electrode feature advantages of low-temperature processability and potential for flexible devices [5,6]. Among the device structure, HTL and ETL serve as auxiliary layers to extract charges from the perovskite layer, deliver the charges to the electrodes, and block the opposite charge transfer [7-10].

Poly(3,4-ethylenedioxythiophene):poly(styrene sulfonate) (PEDOT:PSS) is commonly used for the HTL of inverted PSCs. However, PEDOT:PSS possesses insufficient electron-blocking ability, high hygroscopicity, and poor chemical stability [11-13]. NiOx, being in favor of hole transport and blocking electrons efficiently, is one of the most potential alternatives to PEDOT:PESS [14]. Moreover, NiOx leads to 
higher open-circuit voltage (Voc) of PSCs due to its energy level being more suitable to that of $\mathrm{CH}_{3} \mathrm{NH}_{3} \mathrm{PbI}_{3}$ $\left(\mathrm{MAPbI}_{3}\right)$. To reduce interfacial loss, a passivation layer has been inserted between the perovskite layer and the charge transport layer to decrease interfacial defects and charge recombination [15,16]. Recently, several materials, such as sodium dodecylbenzenesulfonate [17] and polystyrene [18] have been reported to passivate NOx and improve crystal size of perovskite. Although they revealed enhanced efficiency, the studies about how to improve the NOx HTL for PSCs are still few. It remains a challenge to develop new passivation techniques for the NOx HTL of PSCs.

Besides mechanical properties, polyhedral oligomeric silsesquioxane (POSS) has showed its advantage to improve Li batteries [19], light emitting diodes [20], and PSCs [21,22] due to stable electrochemical properties. In this study, we are the first to attempt to use POSS to passivate NOx. The PSCs with fluorine-doped tin oxide (FTO)/NOx/POSS/MAPbI $/ 2 / \mathrm{PC}_{61} \mathrm{BM} / \mathrm{Bathocuproine}(\mathrm{BCP}) / \mathrm{Ag}$ structure were fabricated. The effect of the POSS amount on photovoltaic properties was analyzed. The result showed that the POSS passivation improved significantly crystal size of perovskite, short circuit current (Jsc), and PCE. At 0.01-wt\% POSS, the PCE increase from 13.3 to $15.58 \%$, an enhancement of $17 \%$. This enhancement was mainly due to the increase of the Jsc from 18.0 to 20.5 $\mathrm{mA} / \mathrm{cm}^{2}$, an increase of $13 \%$.

\section{Materials and Methods}

\subsection{Synthesis of NOx Solution}

$0.87 \mathrm{~g}$ of nickel nitrate hexahydrate and $0.12 \mathrm{~g}$ of ethylene diamine were mixed into $5 \mathrm{~mL}$ of ethylene glycol monomethyl ether as. The solution was sealed with parafilm and stirred overnight at $550 \mathrm{rpm}$ and $60{ }^{\circ} \mathrm{C}$. The color of the solution gradually changed from dark green to dark blue, resulting in a $0.6 \mathrm{M}$ NOx solution.

\subsection{Device Fabrication}

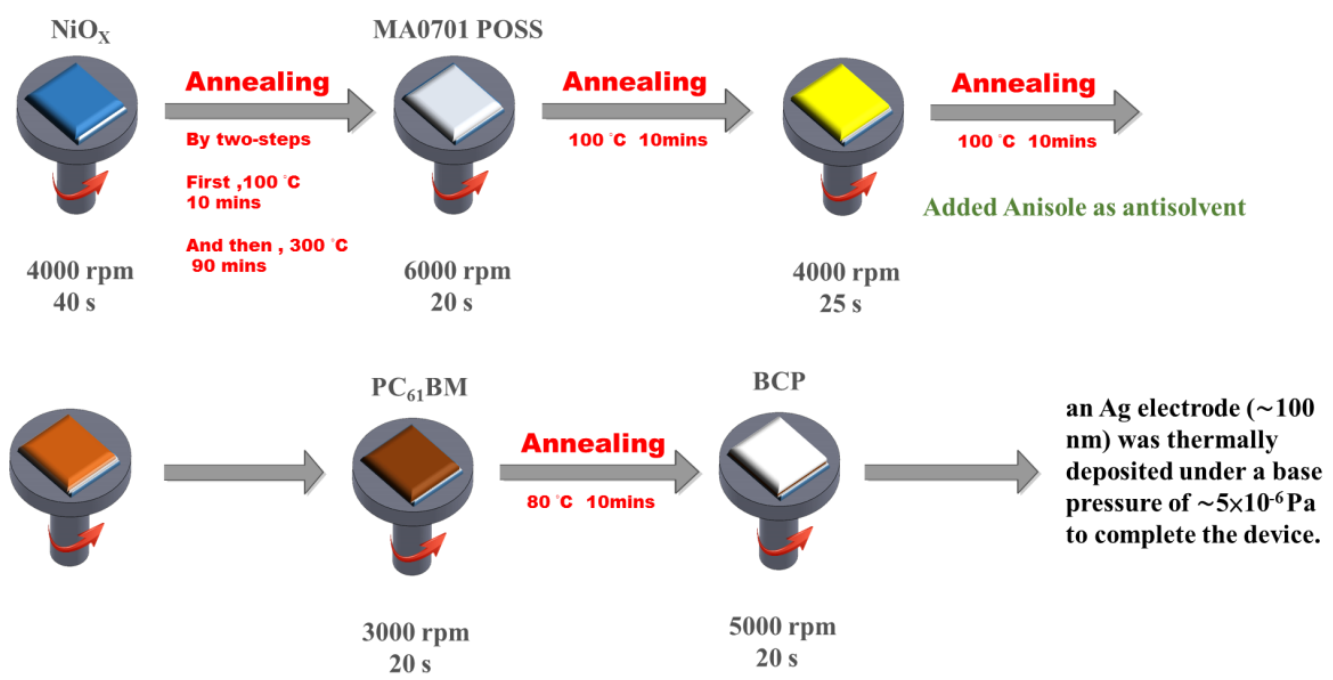




\section{Results}

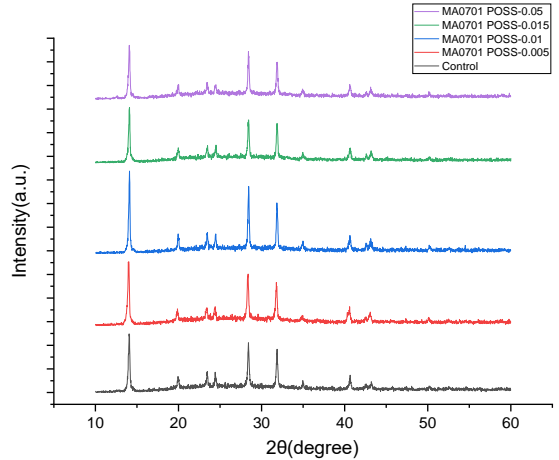

(a)

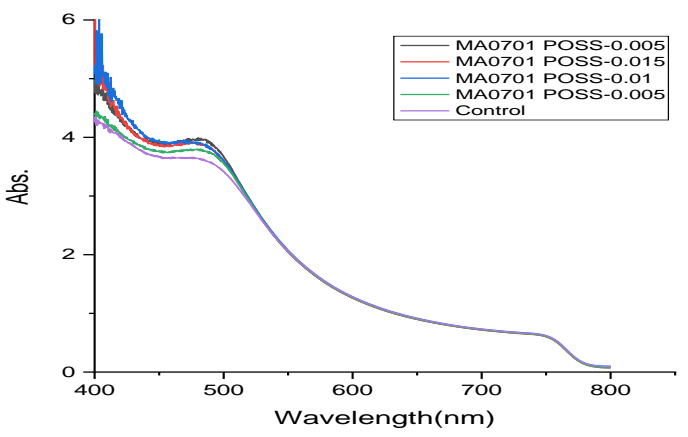

(b)

Figure 1. XRD patterns (a) and UV-Vis curves of the MAPbI 3 layers over the POSS layers fabricated with various concentrations.

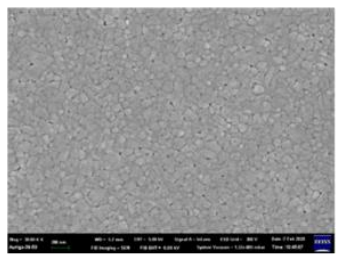

(a) Perovskite

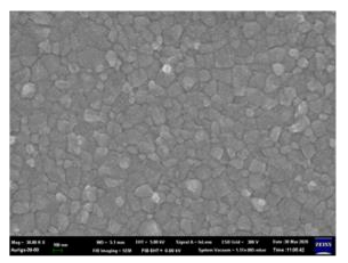

(c) Perovskite + MA0701 POSS-0.005

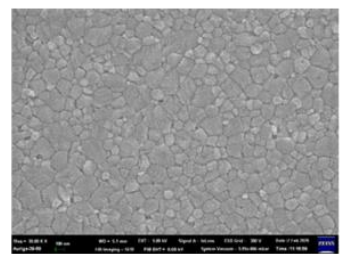

(e) Perovskite + MA0701 POSS-0.01

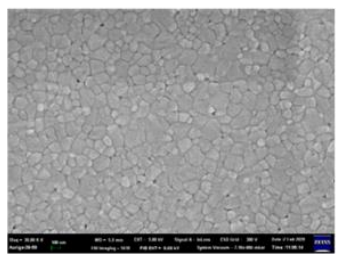

(g) Perovskite + MA0701 POSS-0.015

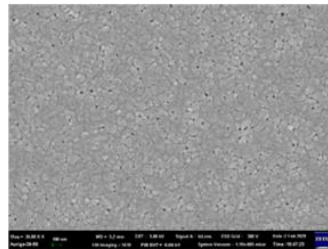

(i) Perovskite + MA0701 POSS- 0.05

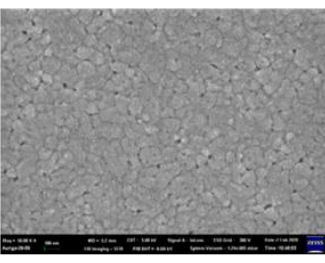

(b) Perovskite

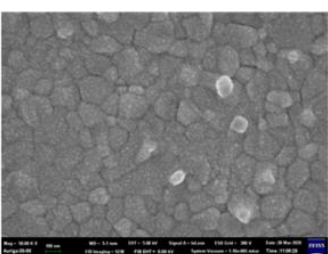

(d) Perovskite + MA0701 POSS-0.005

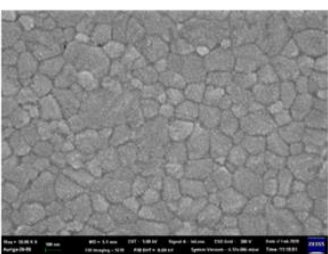

(f) Perovskite + MA0701 POSS-0.01

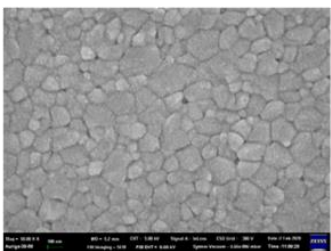

(h) Perovskite + MA0701 POSS-0.015

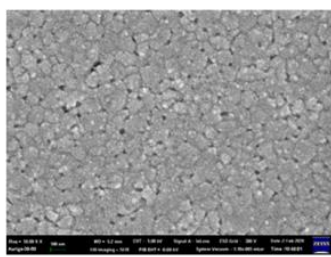

(j) Perovskite + MA0701 POSS-0.05

Figure 2. SEM images of the $\mathrm{MAPbI}_{3}$ layers over the POSS layers fabricated with various concentrations: (a,b) 0, (c,d) 0.005, (e,f) 0.01, (g,h) 0.015, (i,j) $0.05 \mathrm{wt} \%$. 


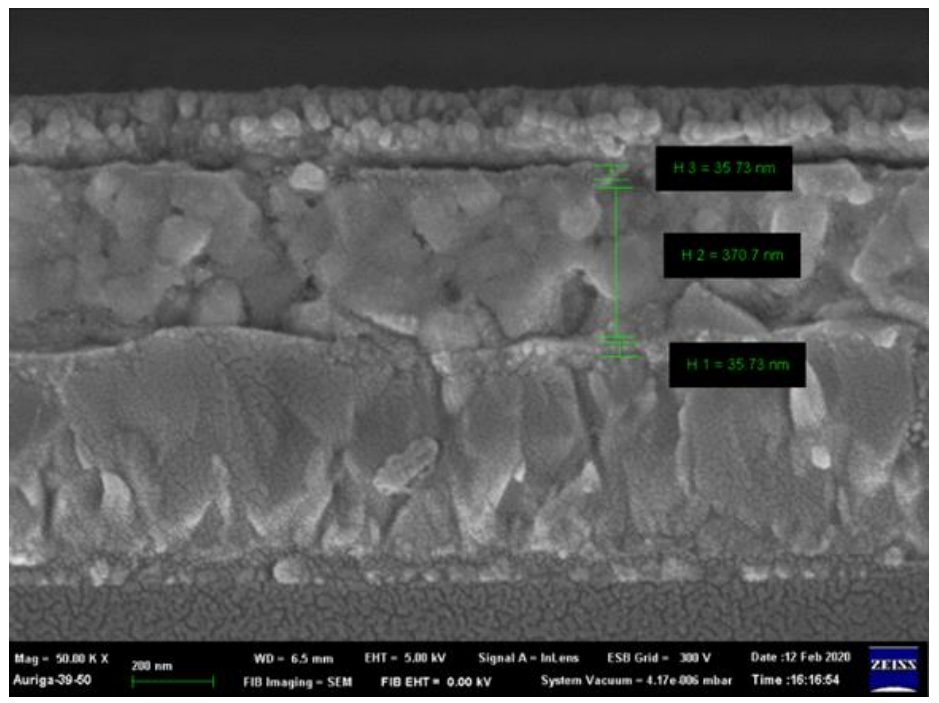

Figure 3. Cross-sectional SEM images of typical PSCs fabricated in this study.

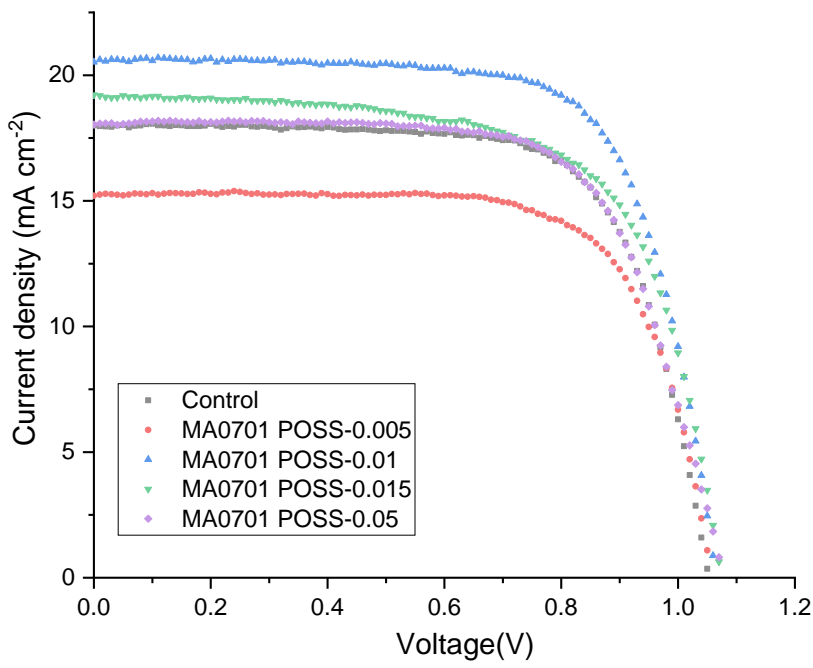

Figure 4. Photocurrent-voltage curves of PSCs fabricated with various POSS concentrations. 
(a)

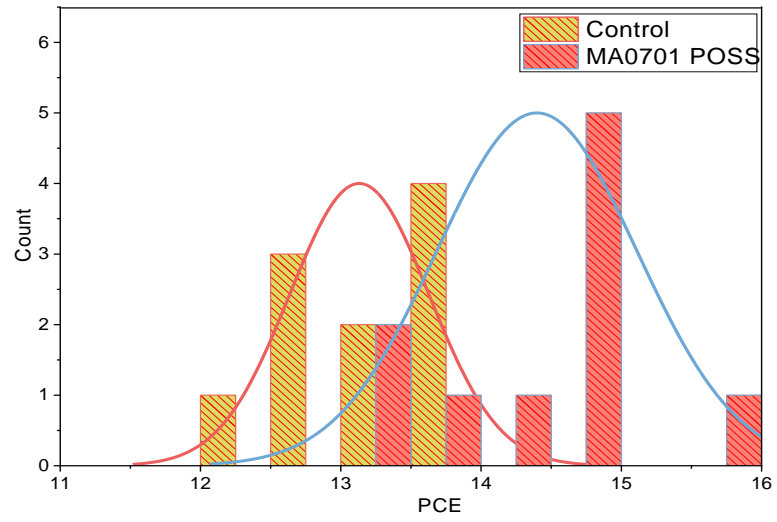

(b)

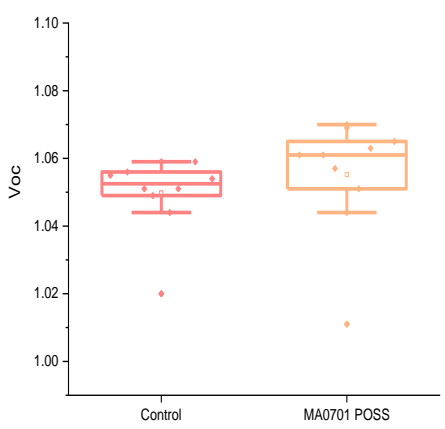

(d)

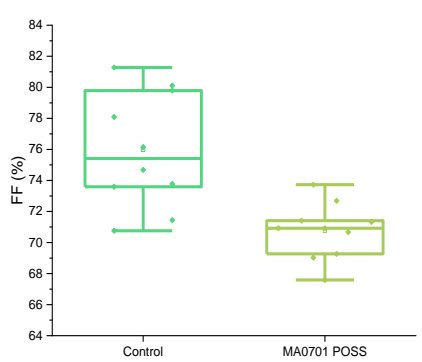

(c)

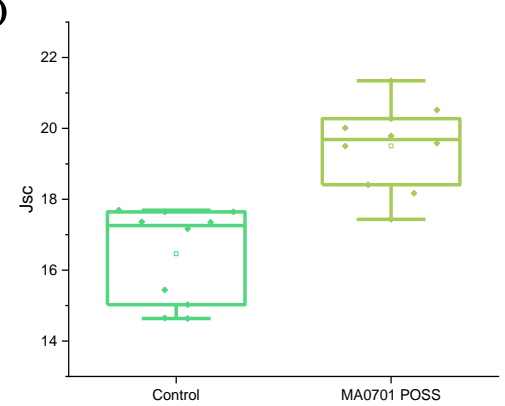

(e)

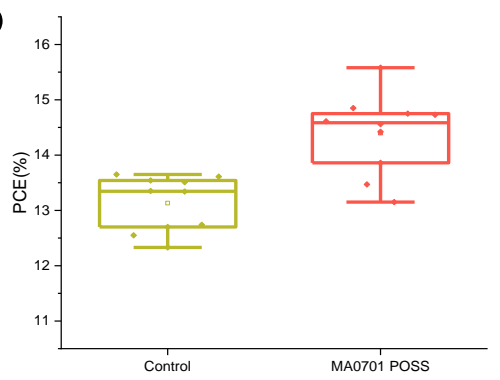

Figure 5. Variations of PCE distribution (a), Voc (b), Jsc (c), FF (d), and average PCE (e) of PSCs fabricated with/without the POSS layer.

Table 1. Photovoltaic characteristics of PSCs fabricated with various POSS concentrations.

\begin{tabular}{|c|c|c|c|c|}
\hline Sample & Voc [volt] & $\mathrm{Jsc}\left[\mathrm{mA} \mathrm{cm}{ }^{-2}\right]$ & $\mathrm{FF}[\%]$ & Average PCE [\%] (Best) \\
\hline Control & 1.053 & 18.004 & 70.18 & $12.55 \pm 0.49\lceil 13.30]$ \\
\hline POSS- 0.005 & 1.048 & 18.391 & 73.78 & $12.64 \pm 1.23\lceil 14.14 〕$ \\
\hline POSS-0.01 & 1.065 & 20.521 & 71.33 & $14.75 \pm 0.71[15.58]$ \\
\hline POSS- 0.015 & 1.074 & 19.222 & 66.16 & $12.85 \pm 0.35[13.66]$ \\
\hline POSS- 0.05 & 1.056 & 15.206 & 71.60 & $10.91 \pm 0.62\lceil 11.50 〕$ \\
\hline
\end{tabular}




\section{Discussion}

The XRD patterns of the perovskite layers over the POSS layer with various amount exhibited two peaks at $14.1^{\circ}$ and $28.4^{\circ}$ (Figure 1a), corresponding to planes (110) and (220), respectively, of the perovskite structure of $\mathrm{MAPbI}$. No peak near $12.7^{\circ}$, attributed to $\mathrm{PbI}_{2}$, was found on the curves. This result implies that POSS incorporation neither hinders the formation of crystal nor results in $\mathrm{PbI}_{2}$ separated out from MAPbIs. Particularly, the peak responding to plane (110) for POSS-0.01 and the UV-Vis absorbance (Figure 1b) are higher than others, indicating that crystallinity is better.

Figure 2 that there are a few tiny voids on the surface of the pristine perovskite layer. When the ultra-thin POSS passivation layer is introduced, the defects is reduced and reaches to the minimum at $0.01 \mathrm{mg} / \mathrm{mL}$ POSS, implying that the coverage of the perovskite layer is more complete. When the POSS is $0.005 \mathrm{mg} / \mathrm{mL}$, the film becomes relatively uneven. However, the voids also increase when the POSS is $0.05 \mathrm{mg} / \mathrm{mL}$. We inferred that too much or too little POSS amount may have a negative impact on the perovskite layer.

Figure 3 shows the cross-sectional image for typical PSCs with the POSS passivation layer in this study. The POSS-0.01 displays the highest PCE (Figure 4 and Table 1). The efficiency increases from 13.30 to $15.58 \%$ due to the POSS passivation layer. The current density increases from 18.0 to 20.5 $\mathrm{mA} / \mathrm{cm}^{2}$, increased by $13 \%$. Figure 5 reveals that the pristine efficiency and current density are about $11 \sim 13 \%$ and $15 \sim 18 \mathrm{~mA} / \mathrm{cm}^{2}$, respectively, without POSS passivation. The POSS passivation increases PCE and Jsc to $13 \sim 15 \%$ and $18 \sim 20 \mathrm{~mA} / \mathrm{cm}^{2}$, respectively. However, the POSS passivation doesn't change significantly the fill factor and Voc.

Author Contributions: B.-T.L. conceptualized the work, designed the experiments, and wrote the manuscript. H.-R.L. conducted the fabrication and measurement of the cells.

Funding: This research was funded by the Ministry of Science and Technology, Taiwan under grant number MOST 108-2221-E-224-026-MY3.

Conflicts of Interest: The authors declare no conflict of interest.

\section{References}

1. Xing, G.; Mathews, N.; Sun, S.; Lim, S.S.; Lam, Y.M.; Grätzel, M.; Mhaisalkar, S.; Sum, T.C. Long-range balanced electron- and hole-transport lengths in organic-inorganic $\mathrm{CH}_{3} \mathrm{NH}_{3} \mathrm{PbI}$. Science 2013, 342, 344-347.

2. Stranks, S.D.; Eperon, G.E.; Grancini, G.; Menelaou, C.; Alcocer, M.J.P.; Leijtens, T.; Herz, L.M.; Petrozza, A.; Snaith, H.J. Electron-hole diffusion lengths exceeding 1 micrometer in an organometal trihalide perovskite absorber. Science 2013, 342, 341-344.

3. Miyata, A.; Mitioglu, A.; Plochocka, P.; Portugall, O.; Wang, J.T.-W.; Stranks, S.D.; Snaith, H.J.; Nicholas, R.J. Direct measurement of the exciton binding energy and effective masses for charge carriers in organicinorganic tri-halide perovskites. Nat. Phys. 2015, 11, 582.

4. De Wolf, S.; Holovsky, J.; Moon, S.-J.; Löper, P.; Niesen, B.; Ledinsky, M.; Haug, F.-J.; Yum, J.-H.; Ballif, C. Organometallic halide perovskites: Sharp optical absorption edge and its relation to photovoltaic performance. J. Phys. Chem. Lett. 2014, 5, 1035-1039.

5. You, J.; Hong, Z.; Yang, Y.; Chen, Q.; Cai, M.; Song, T.-B.; Chen, C.-C.; Lu, S.; Liu, Y.; Zhou, H.; et al. Lowtemperature solution-processed perovskite solar cells with high efficiency and flexibility. ACS Nano 2014, 8, 1674-1680.

6. Docampo, P.; Ball, J.M.; Darwich, M.; Eperon, G.E.; Snaith, H.J. Efficient organometal trihalide perovskite planar-heterojunction solar cells on flexible polymer substrates. Nat. Commun. 2013, 4, 2761.

7. Sacramento, A.S.; Moreira, F.T.C.; Guerreiro, J.L.; Tavares, A.P.; Sales, M.G.F. Novel biomimetic composite material for potentiometric screening of acetylcholine, a neurotransmitter in Alzheimer's disease. Mater. Sci. Eng. C 2017, 79, 541-549.

8. Jiang, Q.; Zhang, L.; Wang, H.; Yang, X.; Meng, J.; Liu, H.; Yin, Z.; Wu, J.; Zhang, X.; You, J. Enhanced electron extraction using $\mathrm{SnO}_{2}$ for high-efficiency planar-structure $\mathrm{HC}\left(\mathrm{NH}_{2}\right)_{2} \mathrm{PbI}_{3}$-based perovskite solar cells. Nat. Energy 2016, 2, 16177.

9. Green, M.A.; Ho-Baillie, A.; Snaith, H.J. The emergence of perovskite solar cells. Nat. Photon. 2014, 8, 506.

10. Edri, E.; Kirmayer, S.; Mukhopadhyay, S.; Gartsman, K.;Hodes, G.; Cahen, D. Elucidating the charge carrier separation and working mechanism of $\mathrm{CH}_{3} \mathrm{NH}_{3} \mathrm{PbI}_{3}-x \mathrm{Cl}_{x}$ perovskite solar cells. Nat. Commun. 2014, 5, 3461. 
11. Li, H.; Fu, K.; Boix, P.P.; Wong, L.H.; Hagfeldt, A.; Grätzel, M.; Mhaisalkar, S.G.; Grimsdale, A.C. Holetransporting small molecules based on thiophene cores for high efficiency perovskite solar cells. ChemSusChem 2014, 7, 3420-3425.

12. Labban, A.E.; Chen, H.; Kirkus, M.; Barbe, J.; Del Gobbo, S.; Neophytou, M.; McCulloch, I.; Eid, J. Improved efficiency in inverted perovskite solar cells employing a novel diarylamino-substituted molecule as PEDOT:PSS replacement. Adv. Energy Mater. 2016, 6, 1502101.

13. Cheng, C.-J.; Balamurugan, R.; Liu, B.-T. Enhanced efficiencies of perovskite solar cells by incorporating silver nanowires into the hole transport layer. Micromachines 2019, 10, 682.

14. Jeng, J.-Y.; Chen, K.-C.; Chiang, T.-Y.; Lin, P.-Y.; Tsai, T.-D.; Chang, Y.-C.; Guo, T.-F.; Chen, P.; Wen, T.-C.; $\mathrm{Hsu}$, Y.-J. Nickel oxide electrode interlayer in $\mathrm{CH}_{3} \mathrm{NH}_{3} \mathrm{PbI}_{3}$ perovskite/PCBM planar-heterojunction hybrid solar cells. Adv. Mater. 2014, 26, 4107-4113.

15. Kim, J.; Ho-Baillie, A.; Huang, S. Review of novel passivation techniques for efficient and stable perovskite solar cells. Solar RRL 2019, 3, 1800302.

16. Peng, J.; Wu, Y.; Ye, W.; Jacobs, D.A.; Shen, H.; Fu, X.; Wan, Y.; Wu, N.; Barugkin, C.; Nguyen, H.T. Interface passivation using ultrathin polymer-fullerene films for high-efficiency perovskite solar cells with negligible hysteresis. Energy Environ. Sci. 2017, 10, 1792-1800.

17. Wang, T.; Xie, M.; Abbasi, S.; Cheng, Z.; Liu, H.; Shen, W. High efficiency perovskite solar cells with tailorable surface wettability by surfactant. J. Power Sources 2020, 448, 227584.

18. Wang, T.; Cheng, Z.; Zhou, Y.; Liu, H.; Shen, W. Highly efficient and stable perovskite solar cells via bilateral passivation layers. J. Mater. Chem. A 2019, 7, 21730-21739.

19. Chinnam, P.R.; Wunder, S.L. Polyoctahedral silsesquioxane-nanoparticle electrolytes for lithium batteries: POSS-lithium salts and POSS-PEGs. Chem. Mater. 2011, 23, 5111-5121.

20. Huang, H.; Lin, H.; Kershaw, S.V.; Susha, A.S.; Choy, W.C.; Rogach, A.L. Polyhedral oligomeric silsesquioxane enhances the brightness of perovskite nanocrystal-based green light-emitting devices. J. Phys. Chem. Lett. 2016, 7, 4398-4404.

21. Liu, N.; Du, Q.; Yin, G.; Liu, P.; Li, L.; Xie, H.; Zhu, C.; Li, Y.; Zhou, H.; Zhang, W.-B. Extremely low trapstate energy level perovskite solar cells passivated using $\mathrm{NH}_{2}-\mathrm{POSS}$ with improved efficiency and stability. J. Mater. Chem. A 2018, 6, 6806-6814.

22. Li, L.; Jin, X.; Liu, N.; Chen, Q.; Zhang, W.B.; Zhou, H. Efficient moisture-resistant perovskite solar cell with nanostructure featuring 3D amine motif. Solar RRL 2018, 2, 1800069.

Publisher's Note: MDPI stays neutral with regard to jurisdictional claims in published maps and institutional affiliations.

(C) 2020 by the authors. Submitted for possible open access publication under the terms and conditions of the Creative Commons Attribution (CC BY) license (http://creativecommons.org/licenses/by/4.0/). 